\title{
A comparative clinical study of intrathecal hyperbaric bupivacaine with and without fentanyl for hysterectomy
}

\author{
Hari Poudel ${ }^{1}$, Surinder Nath Bawa ${ }^{2}$, Surendra Mohan Sharma ${ }^{2}$ \\ ${ }^{1}$ Lecturer, Department of Anaesthesiology, Manipal Teaching Hospital, Phulbari, Pokhara, Nepal, ${ }^{2}$ Professor, \\ Department of Anaesthesiology, Manipal Teaching Hospital, Phulbari, Pokhara, Nepal.
}

Background: Spinal anaesthesia has been widely used for lower abdominal surgeries like hysterectomy. Hyperbaric bupivacaine is the most extensively used local anesthetic. Addition of fentanyl can allow the reduction in the dose of bupivacaine, increase the height and duration of sensory blockade, and reduces complications of spinal anesthesia. Aims and Objective: The aim of the study was to examine whether adding fentanyl to hyperbaric bupivacaine would increase the height of sensory blockade, accelerate the onset of sensory blockade and increase the duration of the sensory blockade. Materials and Methods: This study was done in Manipal Teaching Hospital, Pokhara, Nepal that included hundred patients who underwent total abdominal hysterectomy. The patients were randomly allocated in two groups; Group I: received $0.5 \%$ hyperbaric bupivacaine $2.5 \mathrm{ml}(12.5 \mathrm{mg})$ plus normal saline $0.5 \mathrm{ml}$. Group II: received $0.5 \%$ hyperbaric bupivacaine $2.5 \mathrm{ml}(12.5 \mathrm{mg})$ plus $0.5 \mathrm{ml}$ fentanyl $(25 \mu \mathrm{g})$. Hemodynamic variables, onset of motor and sensory blockade, duration of sensory and motor blockade and any side effects were observed and recorded. Results: The highest and lowest sensory block in Group I was T-7 and T-9 whereas in Group II was T-5 and T-9 respectively.In group I, the mean onset till maximum height of sensory blockade was 7.04 min whereas in group II it was $5.96 \mathrm{~min}(\mathrm{P}<0.00)$. There was no significant statistical difference in the incidence of side effects in both the groups. Conclusion: Intrathecal fentanyl with hyperbaric bupivacaine for spinal anesthesia significantly accelerated the onset of sensory blockade and increased its maximum height and duration.

Key words: Bupivacaine; Fentanyl; Spinal anesthesia
Access this article online

Website:

http://nepjol.info/index.php/AJMS

DOI: 10.3126/ajms.v11i2.26548

E-ISSN: 2091-0576

P-ISSN: 2467-9100

\section{INTRODUCTION}

Spinal anaesthesia is the major regional anaesthesia technique with a long history of effective use for a variety of surgical procedures and pain relief. It produces sympathetic block, sensory analgesia and motor block, depending on dose, concentration, or volume of local anaesthetic. ${ }^{1}$ Nevertheless, precipitous hypotension, operations outlasting the spinal anesthesia and risk of failure are major disadvantages of spinal block. ${ }^{2}$

Opioids and local anesthetics administered together intrathecally have a potent synergistic analgesic effect. ${ }^{3,4}$ Intrathecalfentanyl causes neither by itself nor in combination with bupivacaine any further depression of efferent sympathetic activity, it is possible to enhance the sensory blockade without altering the degree of sympathetic blockade. ${ }^{5}$

Lipophilic opioids (fentanyl and sufentanil) are increasingly being administered intrathecally as adjuvants to local anaesthetics. They enhance spinal anaesthesia without prolonging motor recovery and discharge time. ${ }^{6,7}$

\section{MATERIAL AND METHOD}

After receiving approval from Institutional Review Committee (IRC), this single centered hospital based 
observational analytical study was carried out in Department of Anaesthesiology at Manipal Teaching hospital, Pokhara, Nepal. The study included 100 patients fulfilling the inclusion criteria which are consenting patients of ASA physical status I and II, Age between 20 and 70 years and Patient undergoing Total Abdominal Hysterectomy under spinal anaesthesia.Exclusion criteria were also defined which are Unwilling patients, ASA physical status > III, Patients having the level of sensory block below $\mathrm{T}_{10}$ after 15 minutes, Contraindications to Subarachnoid block, Coagulation disorder or taking any anticoagulant and anti-platelet medicines, Pre-existing neurological or spinal diseases and History of allergy to local anaesthetics and/or opioids. Routine pre-anaesthetic checkup was done one day prior to surgery. Informed and written consent was taken and data collection was done in the preformed collection sheet. All patients were premedicated with diazepam $5 \mathrm{mg}$ per oral at 10 PM the Previous night and fasting from midnight.

On the day of surgery patients were transferred to Pre-anaesthesia preparation room and baselines BP, HR, $\mathrm{SPO}_{2}$ were recorded. IV cannulation was done with 18 G IV cannula and IV fluid Ringer's Lactate infusion was started. The patients were randomly allocated in to groups: Group I: $(n=50)$ received $0.5 \%$ hyperbaric bupivacaine $2.5 \mathrm{ml}(12.5 \mathrm{mg}$ ) plus normal saline $0.5 \mathrm{ml}$ and Group II: $(\mathrm{n}=50)$ received $0.5 \%$ hyperbaric bupivacaine $2.5 \mathrm{ml}(12.5 \mathrm{mg})$ plus $0.5 \mathrm{ml}$ fentanyl $(25 \mu \mathrm{g})$. Study drug was administered intrathecally at L3-L4 intervertebral space with $25 \mathrm{G}$ quincke needle at the rate of $0.2 \mathrm{ml} /$ second after free flow of CSF. Patients were kept in supine position with pillow under head and neck immediately after spinal anaesthesia. BP, HR, ECG, $\mathrm{SPO}_{2}$ was monitored continuously every five minutes. Level of sensory block was defined as the loss of sharp sensation to a pinprick test, and was recorded bilaterally at the midclavicular line. Level of Sensory block assessment was done every minute for 10 minutes after the study drug was given, then at $20 \mathrm{~min}$ and at the end of operation. Onset till the maximum height of sensory block was noted. Surgical procedure was allowed only after the level of sensory block reached $\mathrm{T} 10$ dermatomal level. Intraoperative visual analog scale(VAS) pain score was recorded from the time of surgical incision at 10 minutes interval till the end of surgery. At the end of surgical procedure, the patients were shifted to recovery room and monitored.

Bradycardia was defined as $\mathrm{HR}<50$ beats/min. Hypotension was defined as $20 \%$ decrease in systolic BP from baseline or $\mathrm{SBP}<90 \mathrm{mmHg}$. The following side effects were recorded and rescue treatment was given as mentioned below; Respiratory Depression: Defined as respiratory rate $<10$ breaths/min and classified as Mild:
[SPO $290-94 \%]$ on room air, Moderate: $\left[\mathrm{SPO}_{2}(85-89 \%)\right]$ on room air- treated with $\mathrm{O}_{2}$ via bag and mask and i.v Naloxone (as required), monitored for 100 minutes after initiation of spinal anaesthesia. Pruritus was recorded at the time of complain of symptom and classified as Grade O: no itching, Grade 1: mild not requiring treatment, Grade 2: moderate requiring first line treatment, Grade 3: severe requiring second line treatment. Treatment of Pruritus was done as follows if grade $>2$; First line treatment: IV Promethazine $12.5 \mathrm{mg}$, if not improved by $5 \mathrm{~min}$ then, second line treatment: IV Naloxone $(0.01 \mathrm{ml} / \mathrm{kg})$. The time to first request for therapy for pruritus and the total amount of rescue drug administered were recorded. Nausea and vomiting was recorded at the time of complain of symptom and classified as Grade O: no nausea, Grade 1: mild nausea not requesting treatment, Grade 2: severe nausea requesting treatment, Grade 3: vomiting. Treatment of nausea and vomiting was done if grade $>2$; Treatment was done with IV Metoclapramide $10 \mathrm{mg}$, If not controlled, repeated after $15 \mathrm{~min}$, The time to first request for antiemetic therapy and the total amount of supplemental antiemetic administered were recorded. All other complaints were noted and recorded. For post-operative pain, oral NSAIDS were given as needed, the interval from the injection of spinal anaesthesia to the request of first dose of analgesic was recorded. Data was entered in Excel Master sheet with coding of the variables. SPSS software version 20.0 was used. Frequencies, percentages, means with standard deviation were calculated. Paired sample t-test was used to compare the means between the two groups. P-value was taken as significant if less than 0.05 .

\section{RESULTS}

Hundred ASA I and II female patients aged between 20 to 70 years posted for abdominal hysterectomy under spinal anesthesia were selected for the study. The study was undertaken to evaluate the efficacy of fentanyl $(25 \mu \mathrm{g})$ as adjuvant to hyperbaric bupivacaine $(0.5 \%)$ in comparison with hyperbaric bupivacaine $(0.5 \%)$ with NS $(0.5 \mathrm{ml}$.) for spinal anesthesia. The demographic parameters were comparable between the groups (Table 1).

\begin{tabular}{|c|c|c|c|}
\hline Parameter & Group I & Group II & $p$-value \\
\hline Age (yrs) & $48.42 \pm 9.86$ & $51.04 \pm 10.23$ & 0.196 \\
\hline Weight (Kg) & $50.02 \pm 5.71$ & $48.78 \pm 7.69$ & 0.362 \\
\hline Height (cm) & $150.66 \pm 4.08$ & $151.20 \pm 4.87$ & 0.550 \\
\hline \multicolumn{4}{|l|}{ ASA n (\%) } \\
\hline ASAI & $24(48.0)$ & $22(44.0)$ & 0.688 \\
\hline ASA II & $26(52.0)$ & $28(56.0)$ & \\
\hline
\end{tabular}




\begin{tabular}{|c|c|c|c|}
\hline Parameter & Group I & Group II & p-value \\
\hline Maximum height of sensory blockade & T7-T9 & T5-T9 & \\
\hline Mean height of sensory blockade of Thoracic Segment & $8.26 \pm 0.096$ & $6.74 \pm 0.751$ & $<0.001$ \\
\hline Onset till max height $(\min )$ & $7.04 \pm 0.83$ & $5.96 \pm 0.60$ & $<0.001$ \\
\hline Time for first analgesia (min) & $230.32 \pm 8.58$ & $270.54 \pm 25.08$ & $<0.001$ \\
\hline VAS score at first analgesia & $5.48 \pm 0.64$ & $5.64 \pm 0.69$ & 0.235 \\
\hline
\end{tabular}

The highest and lowest sensory block in Group I was T-7 and T-9 whereas in Group II was T-5 and T-9 respectively. The mean height of sensory blockade in group $\mathrm{I}$ and group II were T-8 and T-7 respectively. ( $\mathrm{p}$-value $<0.001)$ (Table 2).

Heart rate, systolic blood pressure, diastolic blood pressure, mean arterial pressure and oxygen saturations were comparable between groups and did not change significantly in the intraoperative or postoperative period. No adverse events were encountered in either group of patients. Few complications occurred and were treated (Table 3).

\section{DISCUSSION}

Opioids and local anesthetics administered together intrathecally have been shown to have a synergistic analgesic effect. ${ }^{8,9}, 10$ Lipophilic opioids (e.g. fentanyl and sufentanil) are increasingly being administered intrathecally as adjuncts to local anaesthetices. The synergism is characterized by enhanced somatic analgesia without effect on the degree of the local anaesthetic induced sympathetic or motor blockade. ${ }^{11-14}$ The explanation of this synergism is likely due to the drugs separate mechanisms of action, where in inhibition of nociveptive transmission occurs at sequential stage of that signal transmission. Intrathecal opioids inhibit nociceptive afferent synaptic transmission via A delta and $\mathrm{C}$ fiber by opening presynaptic potassium channels to inhibit transmitter release and thus reduce calcium influx. There is also a direct postsynaptic effect with hyperpolarization and reduce neuronal activity along with inhibition of substance P release in dorsal horn of spinal cord..$^{15}$

Local anaesthetics work primarily by causing blockade of voltage-gated sodium channels in the axonal membrane and possibly, a further effect on pre-synaptic inhibition of calcium channel. This leads to a decrease in electrical depolarization, failure to achieve threshold, and a failure to propagate an action potential that culminates in conduction blockade. ${ }^{16}$

In This study, Fentanyl was added to bupivacaine to determine its effect on maximum height of sensory

\begin{tabular}{lcc} 
Table 3: Complications & & \\
\hline Parameter & Group I & Group II \\
\hline Bradycardia & $3 / 50$ & $1 / 50$ \\
Treated for Bradycardia & $1 / 3$ & $\mathrm{Nil}$ \\
Hypotension & $8 / 50$ & $3 / 50$ \\
Treated for Hypotension & $6 / 8$ & $1 / 3$ \\
Nausea/vomiting & $3 / 50$ & $3 / 50$ \\
Treated for Nausea/vomiting & $\mathrm{Nil}$ & $\mathrm{Nil}$ \\
Pruritus & $\mathrm{Nil}$ & $3 / 50$ \\
Treated for Pruritus & $\mathrm{Nil}$ & $\mathrm{Nil}$ \\
Respiratory Depression & $\mathrm{Nil}$ & $\mathrm{Nil}$ \\
Treated for Respiratory Depression & $\mathrm{Nil}$ & $\mathrm{Nil}$ \\
\hline
\end{tabular}

blockade, onset till maximum height, duration of sensory blockade and complications if any. The results suggest that the addition of $25 \mu \mathrm{g}$ of fentanyl to $12.5 \mathrm{mg}$ of bupivacaine (Group II) increased the maximum height of sensory blockade, hastened the onset till the maximum height of sensory blockade, prolonged the total duration of sensory analgesia and cause lesser frequencies of hypotension which was statistically significant.

Study made by Techanivate A et al. ${ }^{17}$ showed that addition of $20 \mathrm{mcg}$ of Fentanyl in $20 \mathrm{mg}$ of bupivacaine prolonged the duration of sensory blockade with no difference in maximum height of sensory blockade and frequencies of complications like hypotension and respiratory depressions. In aspects of hypotension and maximum height of sensory blockade the result differs from the present study. In present study there is lesser frequency of hypotension and the level of the sensory blockade is higher with the addition of fentanyl to bupivacaine. The results of prolonging duration of the sensory blockade and no repertory depression are similar to this study.

The study showed that there is prolongation of the sensory blockade and no significant increase in hypotension similar to the results shown by the study made by Singh $\mathrm{H}$ et. al. ${ }^{18}$ in lower extremities and genitourinary surgeries, whereas it differs that the onset of sensory blockade till the maximum height is unaltered in study made by Singh $\mathrm{H}$ et al.

In the study done by Kumar PN et.al, ${ }^{19} 25$ mcg of fentanyl added to $12.5 \mathrm{mg} 0.5 \%$ bupivacaine in spinal anaesthesia had advantages over conventional dose hyperbaric 
bupivacaine, including faster onset of sensory blockade and longer duration of analgesia which is similar to the results shown by my study.

Likewise, in a study done by Rajnish et al, ${ }^{20}$ the duration of sensory blockade was prolonged in the group who received intrathecal bupivacaine along with fentanyl and the hypotension noted was also significant which is similar as the results in my study.

The study made by Parlow JL et al, ${ }^{21}$ in which showed addition of fentanyl in bupivacaine reduced the density of intrathecal drug injected than the bupivacaine alone. This resulted in higher level of sensory blockade in fentanyl added group which resembles my study result.

Regarding the other side effects, same number of patient from each group had nausea or vomiting not requiring treatment with I.V. ondansetron. This finding was not statistically significant. Similarly, there was no statistical difference in the incidence of bradycardia and pruritus among the groups. Liu Set al, ${ }^{22}$ studied the effect of addition of fentanyl in the quality and duration of lidocaine spinal anesthesia. Pruritus occurred in only subjects receiving fentanyl but was treated easily and was well tolerated.

The administration of intrathecal opioids may provide benefits in augmenting intraoperative anesthesia, butcarries a risk of respiratory depression. ${ }^{23,24}$ But we found no clinical manifestations of respiratorydepression. The similar result was found in as study made by Techanivate A et.al. ${ }^{17}$ which showed that administration of $20 \mu \mathrm{g}$ of fentanyl during spinal anaesthesia did not lead to respiratory depression. Fentanyl is much more lipid-soluble that morphine and hence dose not tend to migrate intrathecally to the fourth ventricle in sufficient concentrations to cause respirator depression.

\section{CONCLUSION}

The addition of $25 \mu \mathrm{g}$ of fentanyl to $12.5 \mathrm{mg}$ of bupivacaine increases the maximum height of sensory blockage, hastens the onset till the maximum height of sensory blockade, prolongs the total duration of sensory analgesia, causes no significant complications like bradycardia respiratory depression, pruritus or nausea and vomiting.

\section{ACKNOWLEDGEMENT}

None.

\section{REFERENCES}

1. Brown DL. Spinal, Epidural and Caudal Anaesthesia. In: Miller RD, Editor, Miller's Anaesthesia, $6^{\text {th }}$ ed. USA: Elsevier
Churchill Livingstone; 2005.p1653.

2. Ankorn $C$ and Casey WF. Spinal Anaesthesia- A Practical Guide. Update in Anaesthesia 1993;3(2):3.

3. Franco CD. Manual of regional Anaesthesia. $2^{\text {nd }}$ ed. Chicago:2007.p18.

4. Harada Y, Nishioka K, Kitahata LM, Kishikawa K and Collins JG. Visceral Antinociceptive Effects of Spinal Clonidine Combined with Morphine, [D-Pen sup 2, D-Pen sup 5] Enkephalin, or U50,488H. Anesthesiology 8 1995; 83:344-352.

5. Wang C, Chakrabart MK and Whitwan JG. Specific enhancement by fentanyl of the effects of intrathecal bupivacaine on nociveptive afferent but not on sympathetic efferent pathways in dogs. Anesthesiology 1993; 79(4):766-763.

6. Bruce DB, Eric S, Hilton L, Hillel A and Zeev G. Intrathecal Fentanyl With Small-Dose Dilute Bupivacaine: Better Anesthesia Without Prolonging Recovery. Anesthesia \& Analgesia 1997; 85(3): 560-565.

7. Chilvers CR, Vaghadia H, Hitchell GW and Merrick PM. Smalldose hypobaric lidocaine-fentanyl spinal anesthesia for short duration outpatient laparascopy. Optimal fentanyl dose. Anesht Analg; 1997:84(1):65-70.

8. Maves TJ and Gebhart GF. Antinociceptive synergy between intrathecal morphine and lidocaine during visceral and somatic nociception in the rat. Anesthesiology 1992;76:91-99.

9. Tejwani GA, Rattena AK and McDonald JS. Role of spina opioid receptors in the antinociceptiv e interactions between intrathecal morphine and bupicacaine. AnesthAnalg 1992;74:726-734.

10. Akerman B, Arwestrom E and Post C. Local anesthetics potentiate spina morphine antinociceptioon. Anesth Analg 1988; 67:943-948.

11. Wulf HF. The centennial of spinal anesthesia. Anesthesiology 1998;89:500-506.

12. Chamberlain DP and Chamberlain BDL. Changes in skin temperature of the truck and their relationship to sympathetic blockade during spinal anesthesia. Anesthesiology 1986; 65:139-145.

13. Matas R. Local and regional anesthesia with cocaine and other analgesic Drugs, including the subarachnoid method, as applied in the general surgical practice. Phil Med J 1900;68:20-43.

14. Vandam LD. On the origins of intrathecal anesthesia. RegAnesth Pain Med 1998; 23:335-339.

15. Shrivastav U, Kumar A, Saxena S, Saxena R, Gandhi NK and Salar P. Spinal anaesthesia with lignocaine and fentanyl. Indain J. Anaesth 2004; 48(2):121-123.

16. Lambert DH. Pharmacology of Local Anesthetics. Outline for Pharmacology of Local anesthetics. http://www.debunkit.org/ Don\%20Lambert\%27s\%20Presentations/Pharmacology_ Syllabus_2005.pdf

17. Techanivate $A$, Urusopone $P$, Kiatgungwanglia $P$ and Kosawiboonpol R. Intrathecal fentanyl in spinal anaesthesia for appernectomy. J med assoc Thai 2004; 87(5):525-30.

18. Singh $\mathrm{H}$. Yang J, Thornton $\mathrm{K}$ and Giesecke AH. Intrathecal fentanyl prolongs sensory bupcvacaine spinal block. Canadian Journal of Anaesthesia 1995.

19. Kumar PN and Shetty K. Abstracts of free scientific papers. $57^{\text {th }}$ Annual National Conference of Indian Society of Anesthesiologists; 2009 Dec 26-29; Tamil Nadu, India:37.

20. Jain RK, Duggal R and Agarwal RC. Comparative study of Intrathecal Hyperbaric Bupivancaine v/s Bupivacaine \& Fentanyl for TURP. American Society of Anesthesialolgists 2007;107:383.

21. Parlow JL, Money P, Chan PS, Raymond J Milne B. Addition of opioids alters the density and spread of intrathecal local anaesthetics? An in vitro study. Canadian Journal of Anaesthesia 1999; 46(1):66-70. 
22. Liu S, Chiu A, Carpenter R, Mulroy MF, Allen HW, Neal JM, et al. Fentanyl prolongs lidocaine spinal anesthesia without prolonging recovery. Anesth Analg 1995;80(4):730-734

23. Etches R, Sandler A and Daley M. Respiratiory depression and spinal opioids. Can J Anaesth 1989; 36:165-185.

24. Varrassi G, Celleno D, Capogna G, Costantino P, Emanuelli M, Sebastiani M, et al. Ventilatory effects of subarachnoid fentanyl in the elderly. Anaesthesia 1992; 47(7):558-562.

Authors Contribution:

HP- Concept and design, review of literature, statistically analysis and interpretation, manuscript preparation and revision; SNB- literature search and review; SMS- Manuscript revision and literature review.

Work attributed to:

Department of Anaesthesiology, Manipal Teaching Hospital, Phulbari, Pokhara, Nepal.

\section{Orcid ID:}

Dr. HariPoudel - (10 https://orcid.org/0000-0002-9168-6620 